Supporting Information

\title{
Degradation of the Nitrification Inhibitor 3,4-Dimethylpyrazole Phosphate in Soils: Indication of Chemical Pathways
}

Parvinder K. Sidhu, ${ }^{a}$ Bethany I. Taggert, ${ }^{a}$ Deli Chen ${ }^{\mathrm{b}}$ and Uta Wille ${ }^{\mathrm{a} *}$

aSchool of Chemistry, Bio21 Institute, The University of Melbourne, 30 Flemington Road, Parkville, Victoria 3010, Australia.

${ }^{b}$ School of Agriculture and Food, The University of Melbourne, 142 Royal Parade, Parkville, Victoria 3010, Australia.

Email: uwille@unimelb.edu.au

Table of Contents

1. SUPPLEMENARY TABLES AND FIGURES

2. CHARACTERIZATION OF REACTION PRODUCTS... 


\section{Supplemenary Tables and Figures}

Table S1. Recovery rate of DMP from soil extractions (Casino soil, $\mathrm{pH} 6.8 ; 10 \mathrm{~g}$ dry soil weight) ${ }^{a}$

\begin{tabular}{cc}
\hline $\begin{array}{c}\text { DMP application rate } \\
\left(\mathbf{m g ~ k g}^{-\mathbf{1}} \mathbf{d r y} \text { soil }\right)\end{array}$ & DMP recovery $(\%)^{\boldsymbol{b}}$ \\
\hline 1.3 & $78.5 \pm 4.5$ \\
2.5 & $77.9 \pm 3.8$ \\
3.8 & $75.7 \pm 2.1$
\end{tabular}

$\overline{{ }^{a}}$ Determined by HPLC, using the optimised method (see Materials and Methods section in paper). ${ }^{b}$ Mean values $(\mathrm{n}=3)$; errors are standard errors of the mean. 

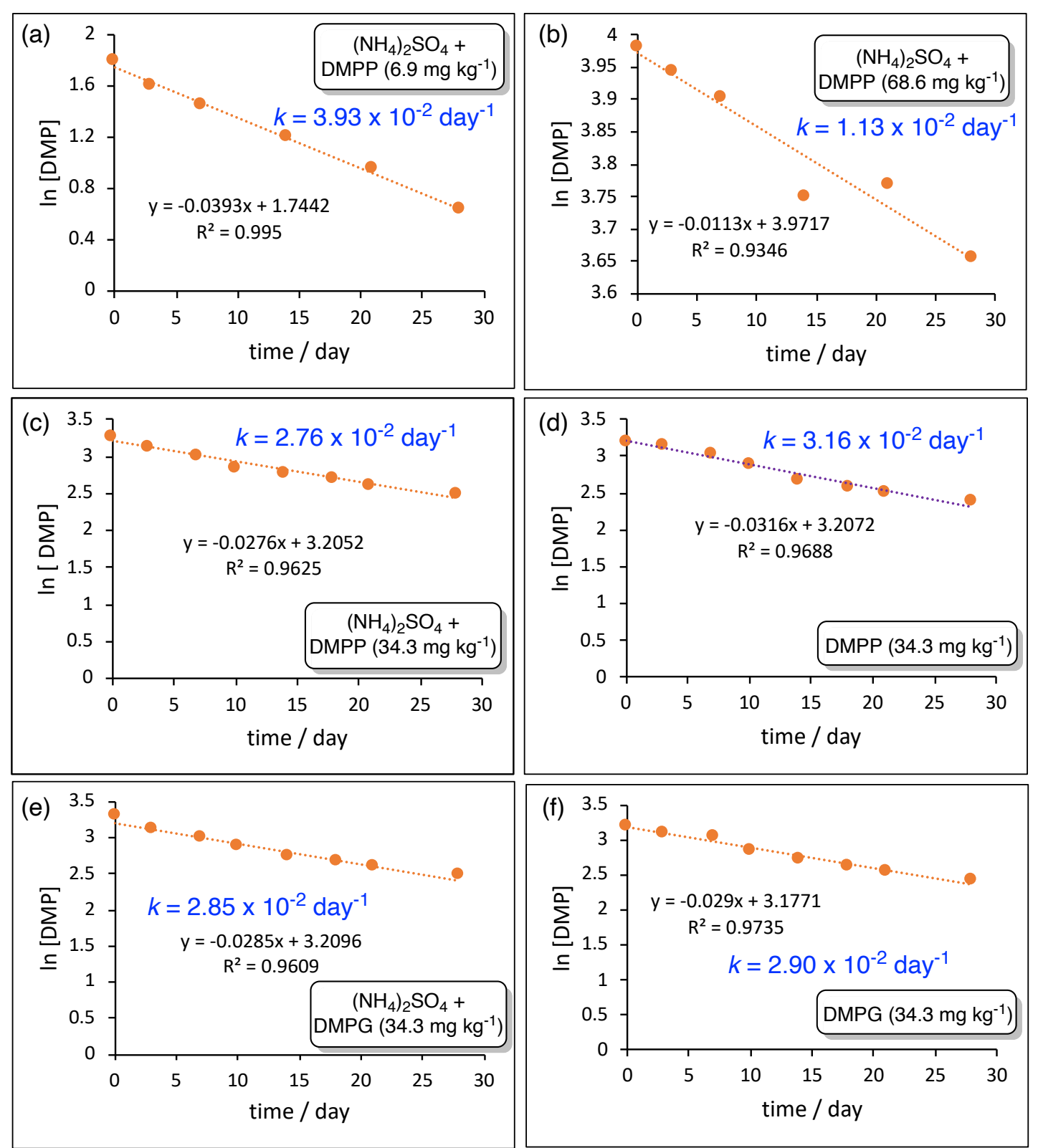

Figure S1. Plots of $\ln [\mathrm{DMP}]$ over time to determine the first-order rate coefficients $(k)$ for the decay of DMP in two different soils at different application rates (28 days of incubation at $\left.25^{\circ} \mathrm{C}\right)$. (a) and (b): Horsham soil (clay, $\mathrm{pH} 8.8$ ) with (a) $\left(\mathrm{NH}_{4}\right)_{2} \mathrm{SO}_{4}+$ DMPP $\left(6.9 \mathrm{mg} \mathrm{kg}^{-1}\right.$ dry soil; $1 \mathrm{~mol} \%$ of fertilizer $\mathrm{N})$ and (b) $\left(\mathrm{NH}_{4}\right)_{2} \mathrm{SO}_{4}+$ DMPP $\left(68.6 \mathrm{mg} \mathrm{kg}^{-1}\right.$ dry soil, $10 \mathrm{~mol} \%$ of fertilizer N). (c) and (d): Dooen (clay, $\mathrm{pH} 8.4)$ with (c) $\left(\mathrm{NH}_{4}\right)_{2} \mathrm{SO}_{4}$ and DMPP (34.3 mg kg-1 dry soil; $5 \mathrm{~mol} \%$ of fertilizer $\mathrm{N}$ ) and (d) water and DMPP (34.3 $\mathrm{mg} \mathrm{kg}^{-1}$ dry soil), no $\left(\mathrm{NH}_{4}\right)_{2} \mathrm{SO}_{4}$ (control). (e) and (f): Dooen (clay, $\mathrm{pH} 8.4)$ with (a) $\left(\mathrm{NH}_{4}\right)_{2} \mathrm{SO}_{4}$ and DMPG (34.3 mg kg-1 dry soil; $5 \mathrm{~mol} \%$ of fertilizer $\mathrm{N}$ ) and (d) DMPG in water (34.3 $\mathrm{mg} \mathrm{kg}^{-1}$ dry soil), no $\left(\mathrm{NH}_{4}\right)_{2} \mathrm{SO}_{4}$ (control).

The half-life, $t_{1 / 2}$, was calculated according to: $t_{1 / 2}=\ln 2 / k$ 

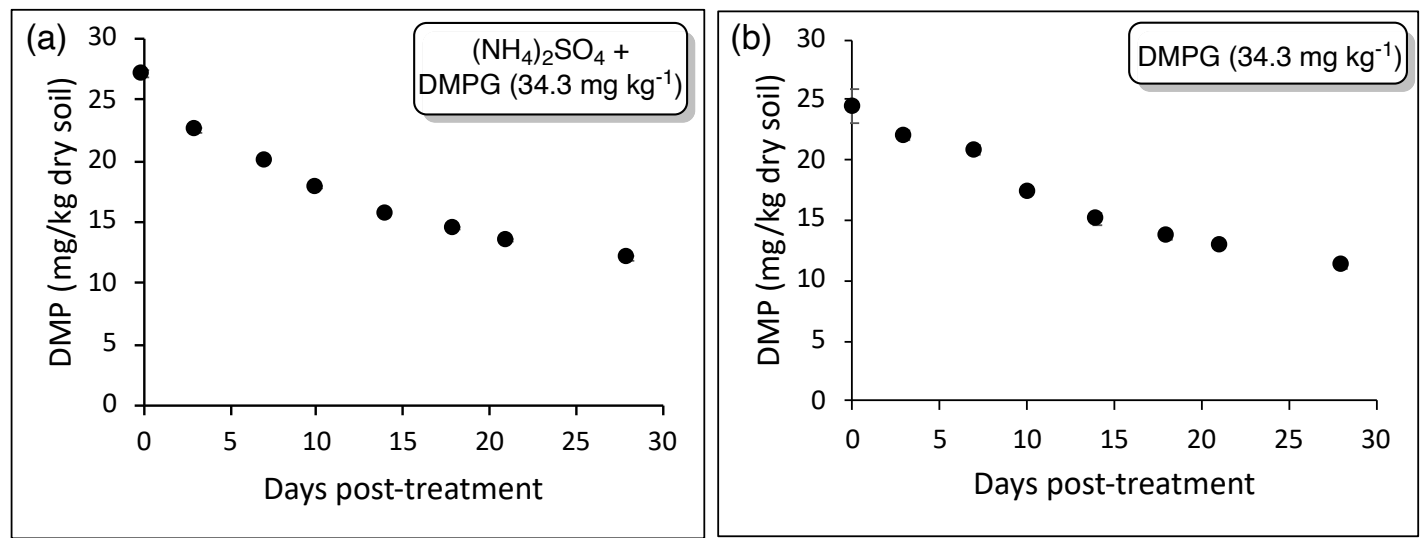

Figure S2. DMP concentration profiles over a 28 -day incubation study at $25^{\circ} \mathrm{C}$. (a) and (b): Dooen (clay, pH 8.4) with (a) $\left(\mathrm{NH}_{4}\right)_{2} \mathrm{SO}_{4}$ and DMPG $\left(34.3 \mathrm{mg} \mathrm{kg}^{-1}\right.$ dry soil; $5 \mathrm{~mol} \%$ of fertilizer N) and (d) DMPG (34.3 $\mathrm{mg} \mathrm{kg}^{-1}$ dry soil) in water, no $\left(\mathrm{NH}_{4}\right)_{2} \mathrm{SO}_{4}$; extraction on day $0,3,7,10,14,18,21$ and 28 post-treatment. Mean values $(n=3)$; errors are standard errors of the mean.

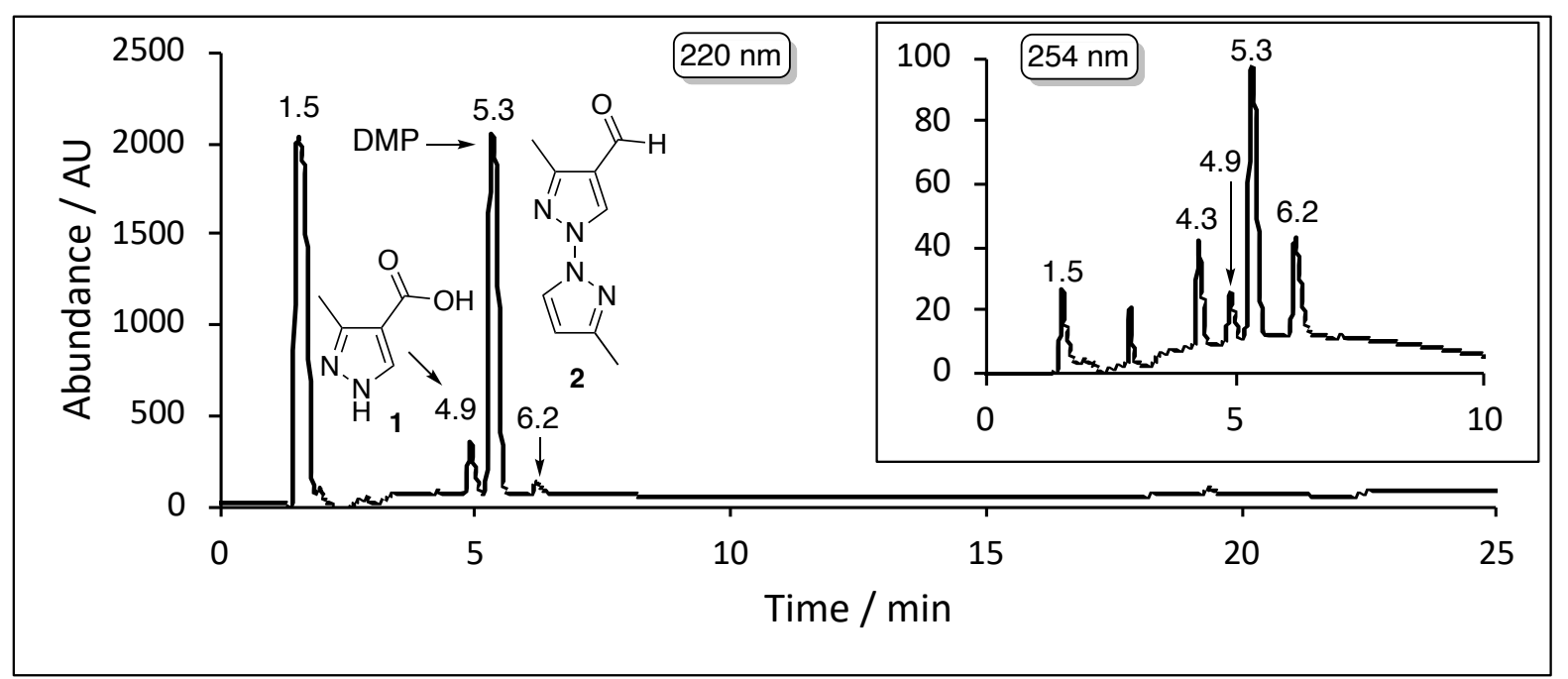

Figure S3. HPLC chromatogram of the aqueous soil extract (Dooen soil) for the treatment $\left(\mathrm{NH}_{4}\right)_{2} \mathrm{SO}_{4}$ and DMPG (500 mg kg-1 dry soil; $73 \mathrm{~mol} \%$ of applied fertilizer $\mathrm{N}$ ) after an incubation time of 63 day at $25^{\circ} \mathrm{C}$, recorded at $220 \mathrm{~nm}$. The inset shows a section of the chromatogram recorded at $254 \mathrm{~nm}$. Products were identified by HRMS analysis, following separation by HPLC. The numbers on the peaks are retention times (in minutes). 

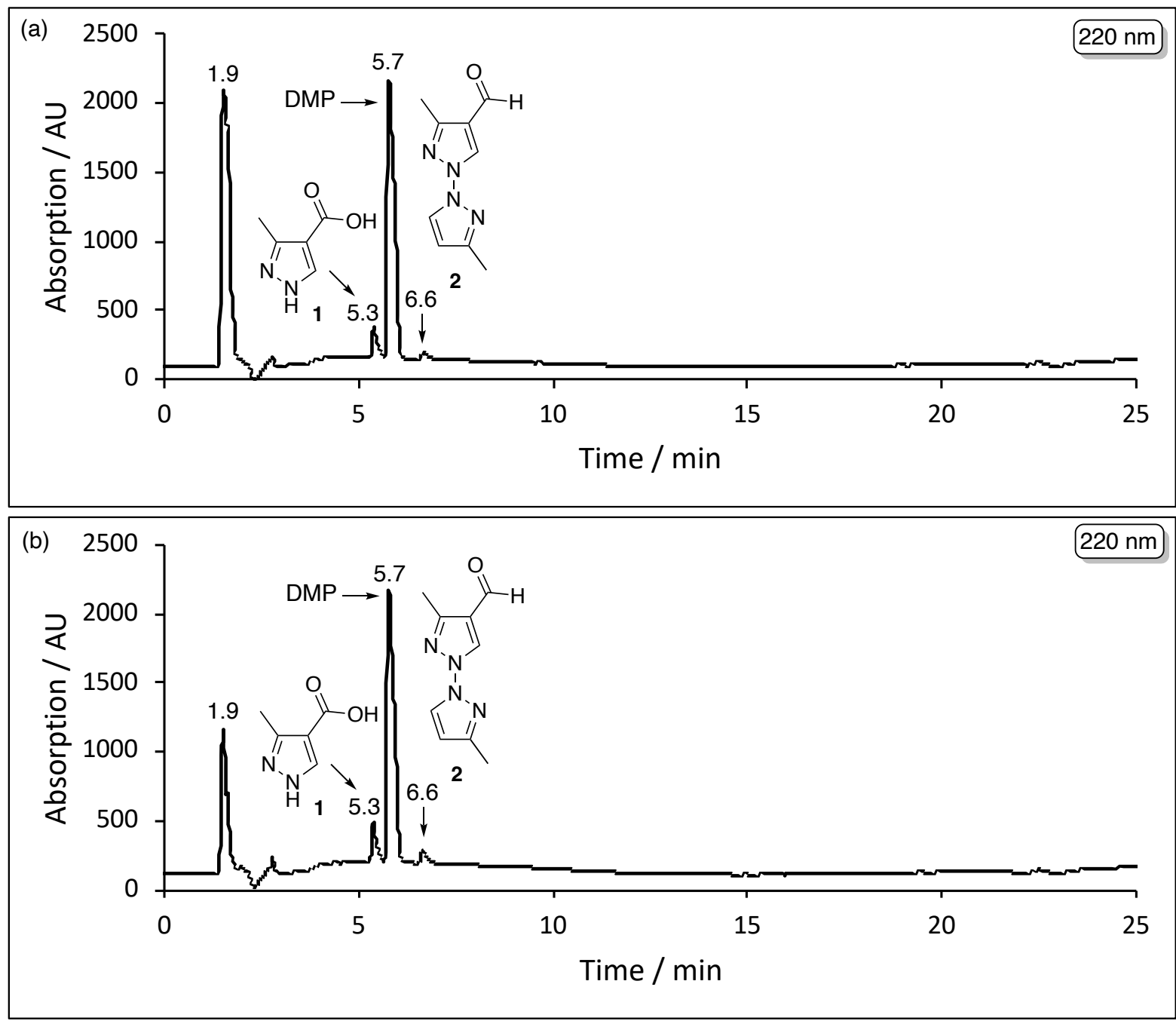

Figure S4. HPLC chromatogram of the aqueous soil extract for the treatment $\left(\mathrm{NH}_{4}\right)_{2} \mathrm{SO}_{4}$ and DMPG (500 mg kg-1 dry soil; $73 \mathrm{~mol} \%$ of applied fertilizer $\mathrm{N}$ ) after an incubation time of 56 days at $35^{\circ} \mathrm{C}$, recorded at $220 \mathrm{~nm}$. (a) Dooen soil untreated, (b) Dooen soil sterilized by autoclaving. The numbers on the peaks are retention times (in minutes). 


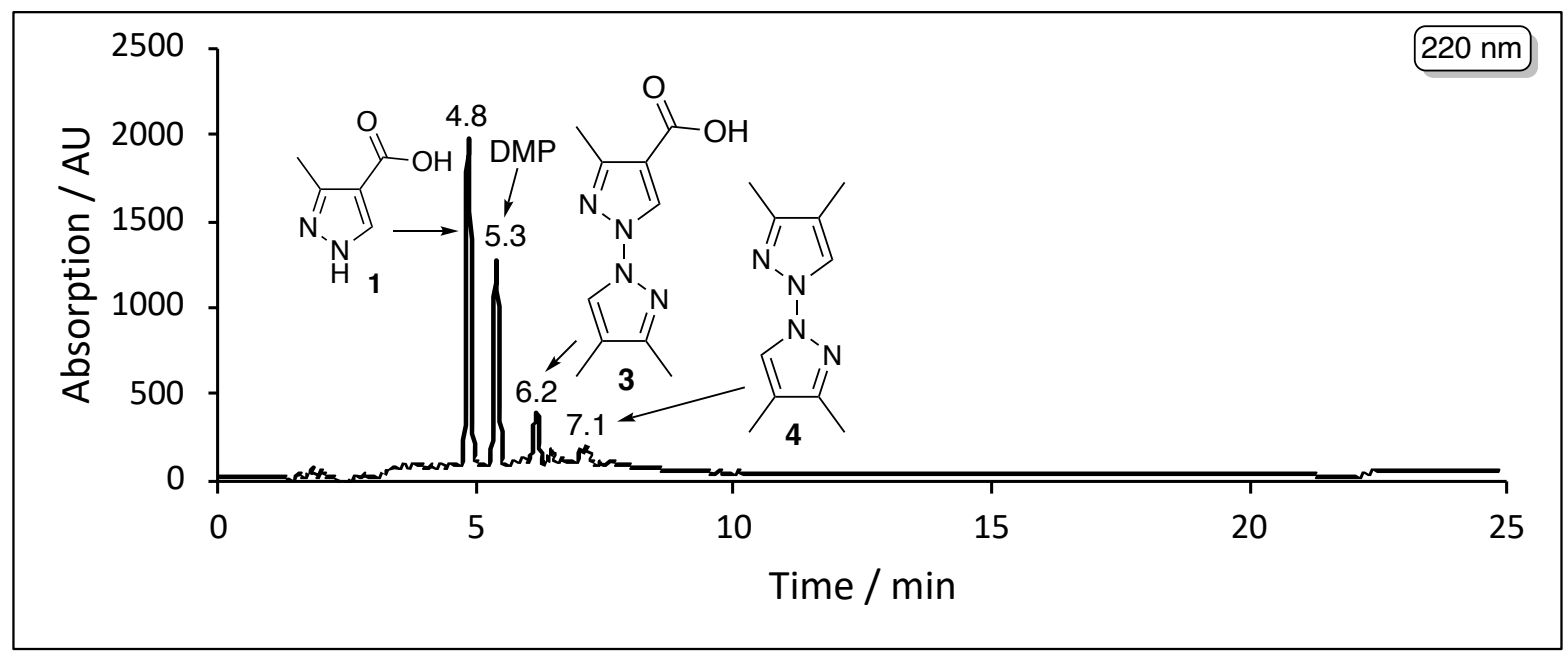

Figure S5. HPLC chromatogram of the reaction mixture of DMPG (ca. $2 \mathrm{mg} \mathrm{mL}^{-1}$ of aqueous $\left(\mathrm{NH}_{4}\right)_{2} \mathrm{SO}_{4}\left(3.14 \mathrm{~g} \mathrm{~L}^{-1}\right)$ solution) after 168 hours of accelerated weathering. Weathering cycle: $0.68 \mathrm{~W} \mathrm{~m}^{-2} \mathrm{UV}$ irradiance for $8 \mathrm{~h}$ at $50^{\circ} \mathrm{C}$, followed by $4 \mathrm{~h}$ of condensing humidity. Products were identified by HRMS analysis (in the case of 1 also by NMR spectroscopy), following separation by HPLC. The numbers on the peaks are retention times (in minutes).

Identical products were formed in the accelerated weathering studies of DMPP under similar conditions.

\section{A general note regarding the HPLC retention times:}

All HPLC runs were performed over a period of several months. Minor modifications were made to the HPLC instrument over this time, which led to slight shifts of the peaks. For each experiment the identity of the signals was confirmed by HRMS analysis after separation by HPLC, in addition to re-running the HPLC analyses for several samples after such modifications. 


\section{Characterization of Reaction Products}

3-Methyl-1H-pyrazole-4-carboxylic acid (1)

${ }^{1} \mathrm{H}$ NMR (500 MHz, DMSO-d $) \delta 7.83(1 \mathrm{H}, \mathrm{s}), 2.37$ (3H, s). ${ }^{13} \mathrm{C}$ NMR (126 MHz, DMSO-d 6 ) $\delta 165.32,145.49,139.19,111.45,11.79$. HRMS $($ ESI + ) $m / z$ : $\left[\mathrm{C}_{5} \mathrm{H}_{6} \mathrm{~N}_{2} \mathrm{O}_{2}+\mathrm{H}\right]^{+}$calculated 127.0503, found 127.0503.

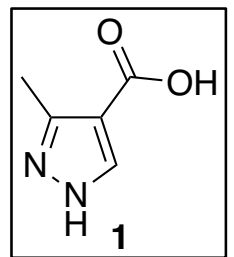

${ }^{1} \mathrm{H}$ NMR spectrum:

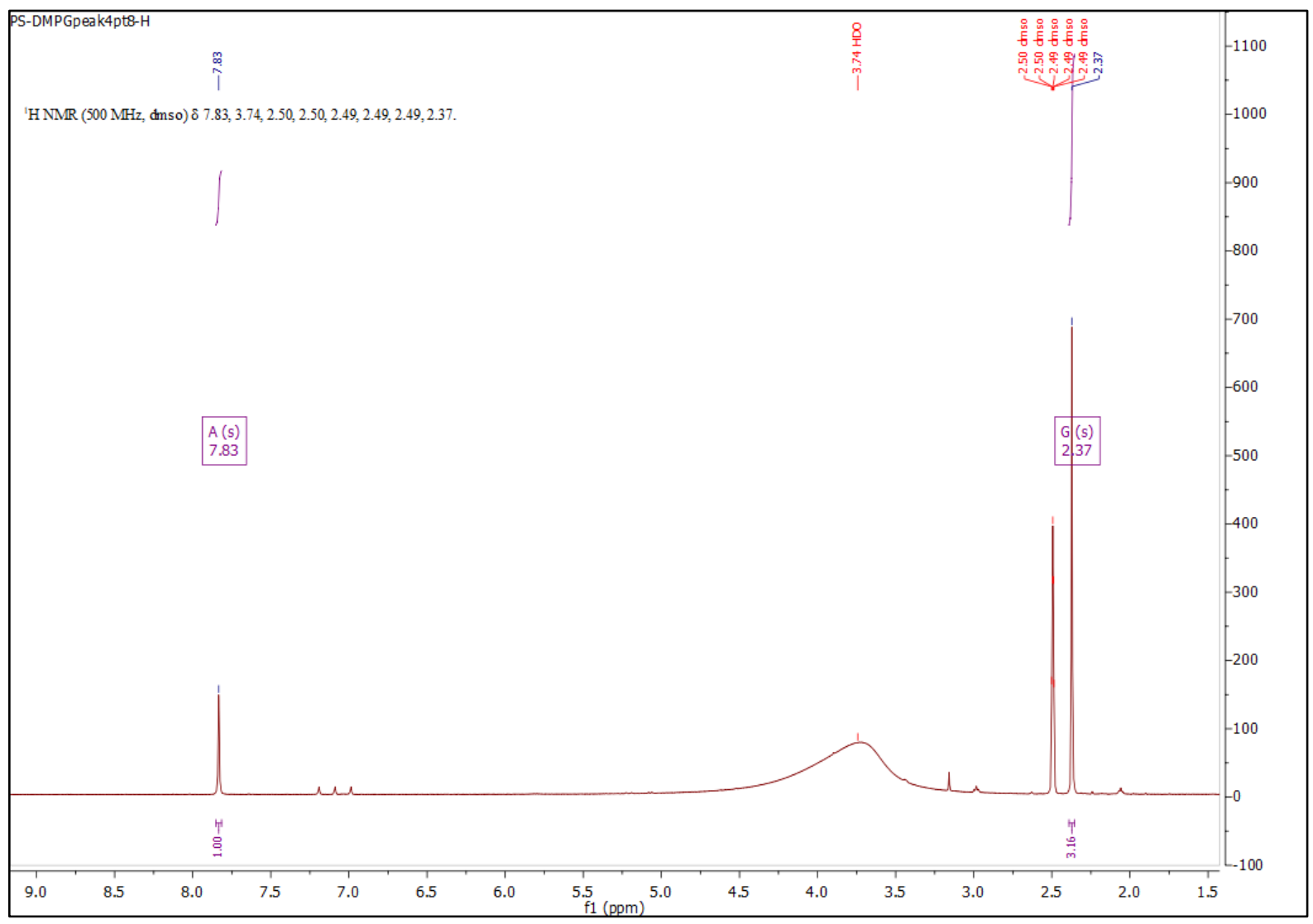


${ }^{13} \mathrm{C}$ NMR spectrum:

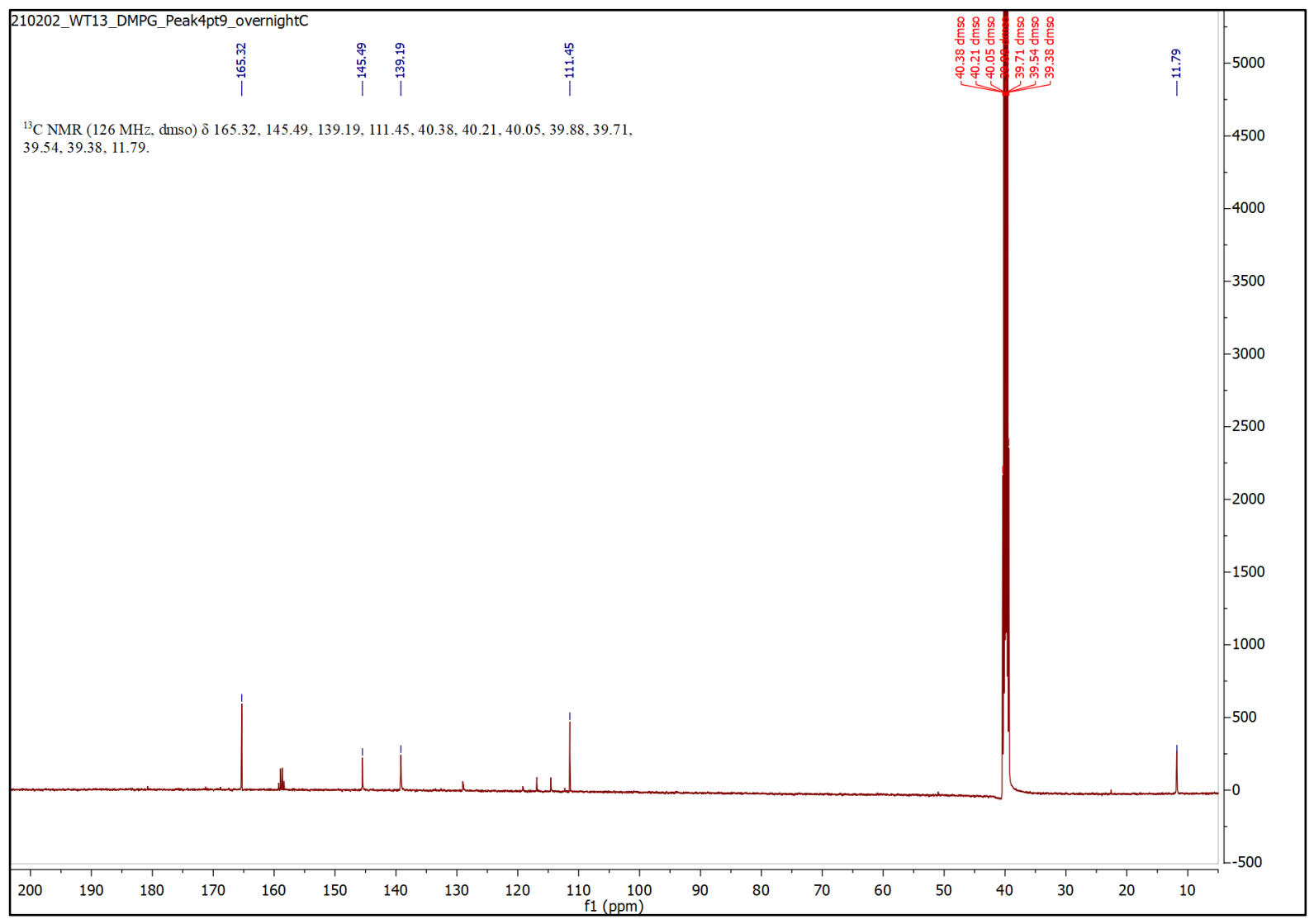


HRMS:

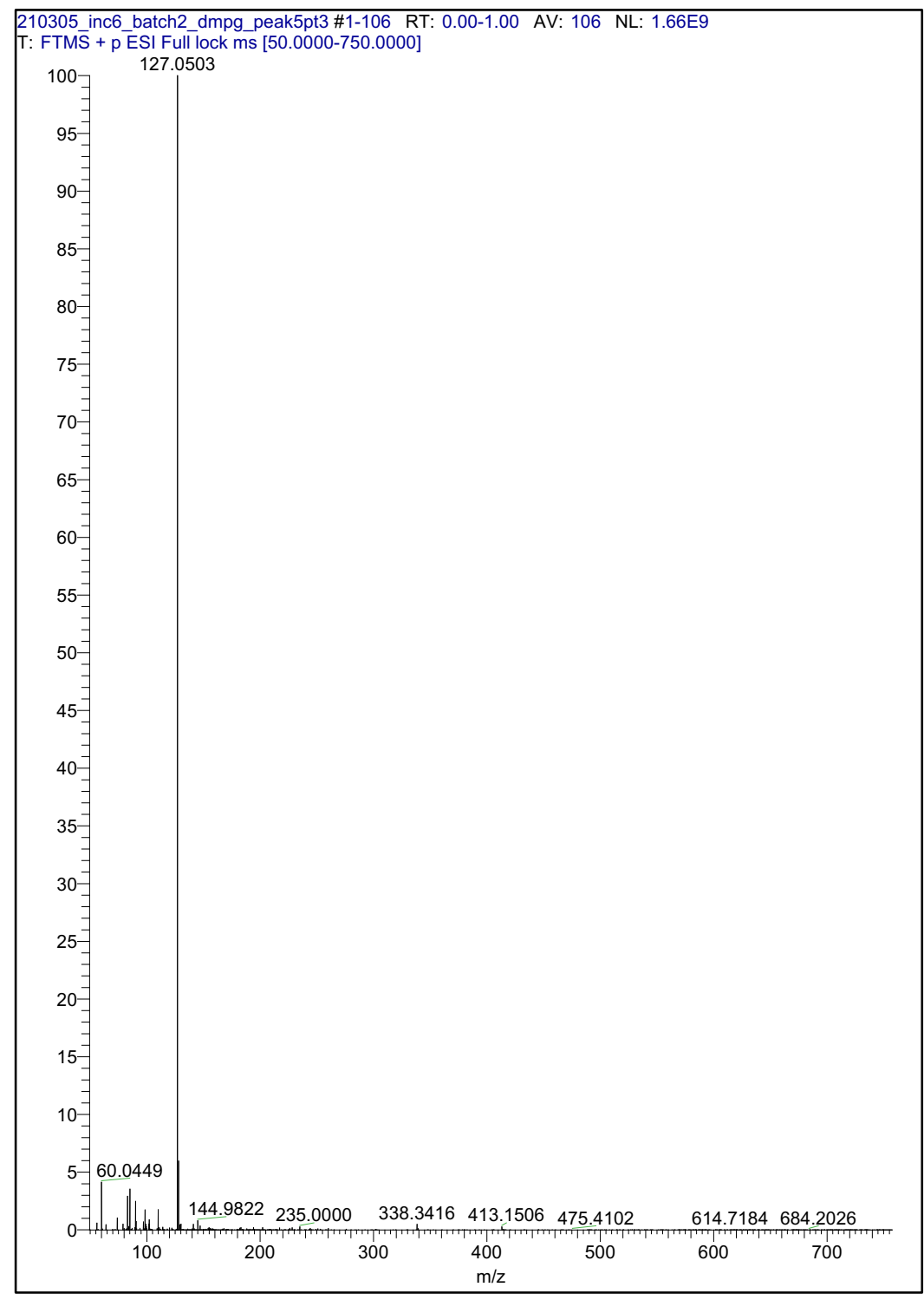

Note: Control runs confirmed that the other signals in the HRMS were background noise from the instrument. Depending on the amount of product formed, their intensity varied considerably. 


\section{Dimer 2 (from soil incubation study)}

Observed mass at $m / z=191.0925$ (in agreement with molecular formula $\mathrm{C}_{9} \mathrm{H}_{10} \mathrm{~N}_{4} \mathrm{O}\left([\mathrm{M}+\mathrm{H}]^{+}\right.$: calcd $m / z=191.0928)$ ). Tentative structure assignment.

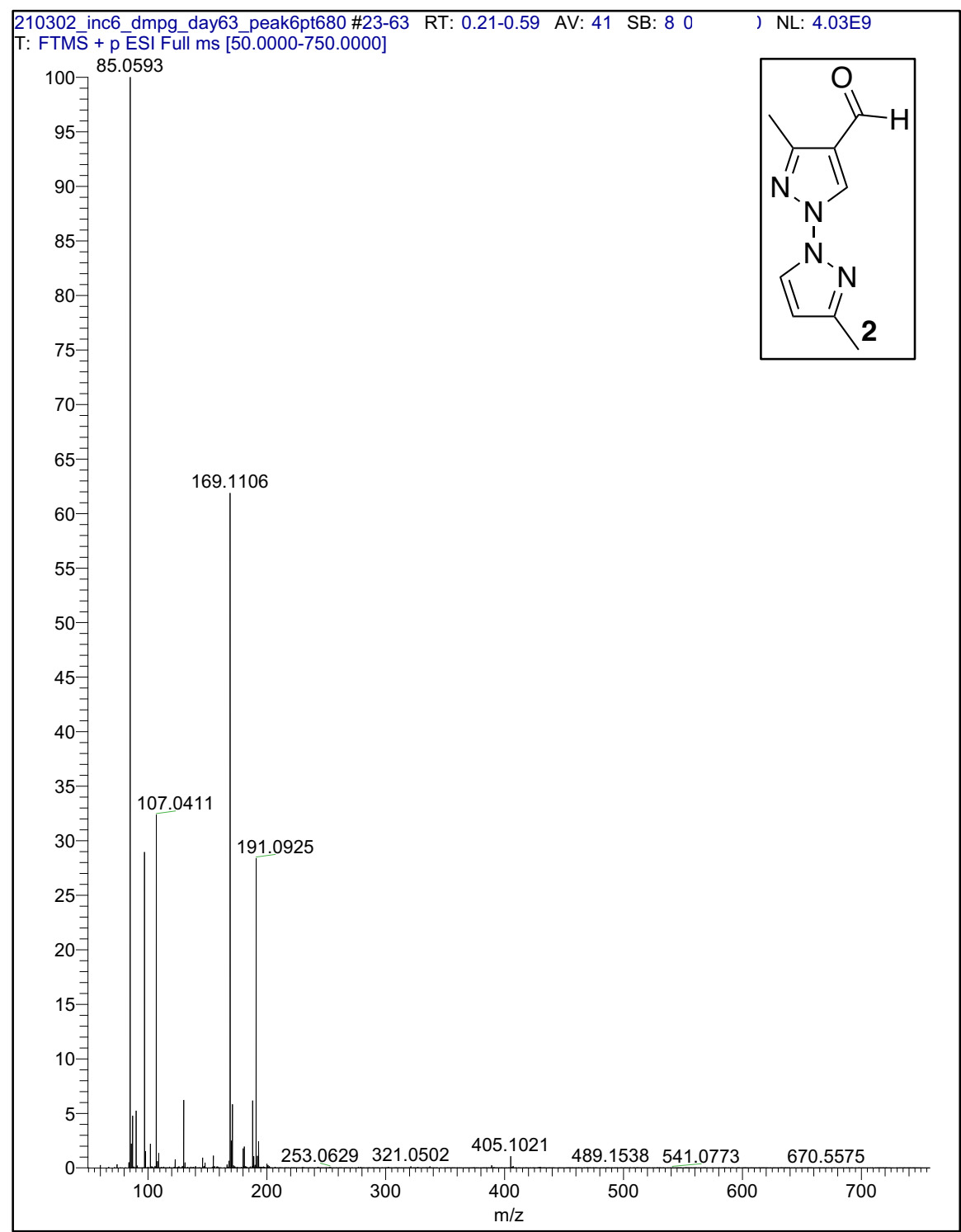




\section{Dimer 3 (from accelerated weathering study)}

Observed mass at $m / z=221.1027$ (in agreement with molecular formula $\mathrm{C}_{10} \mathrm{H}_{12} \mathrm{~N}_{4} \mathrm{O}_{2}\left([\mathrm{M}+\mathrm{H}]^{+}\right.$: calcd $m / z=221.1034)$. Tentative structure assignment.

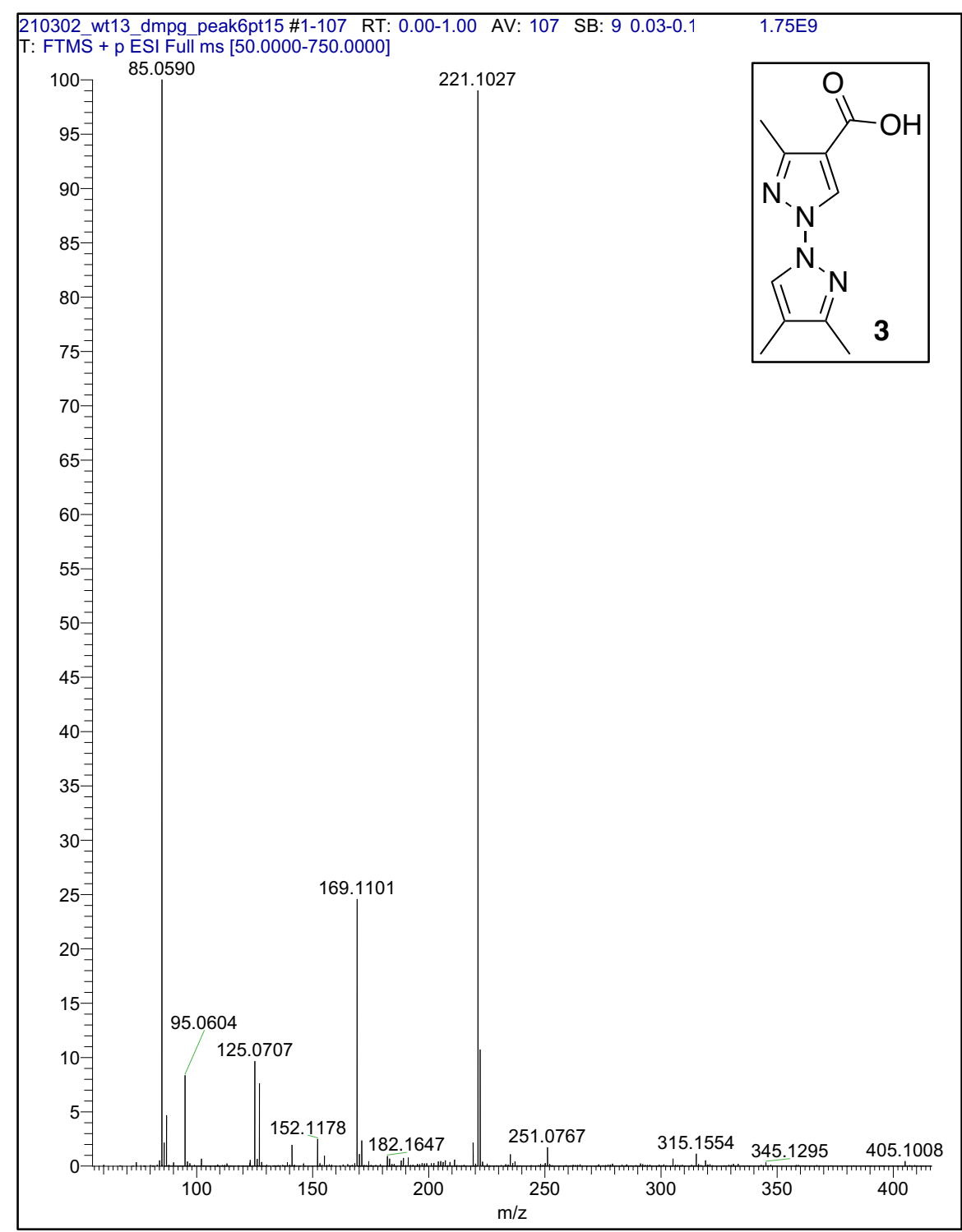




\section{Dimer 4 (from accelerated weathering study)}

Observed mass at $m / z=191.1292$ (in agreement with molecular formula $\mathrm{C}_{10} \mathrm{H}_{14} \mathrm{~N}_{4}\left([\mathrm{M}+\mathrm{H}]^{+}\right.$: calcd $m / z=191.1292)$ ). Tentative structure assignment.

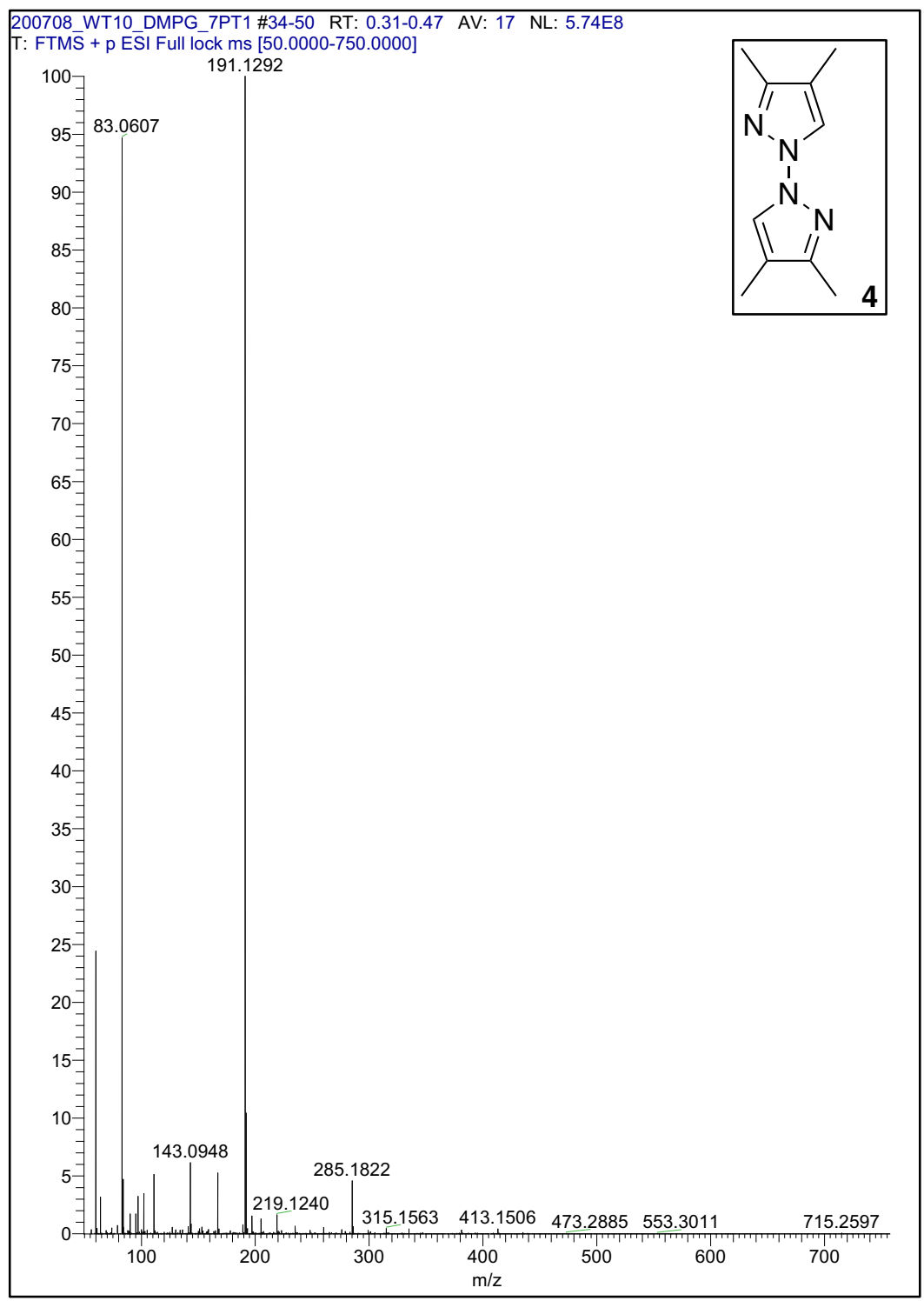

